\title{
Chlorophyll Fluorescence Transient Analysis in Alternanthera tenella Colla Plants Grown in Nutrient Solution with Different Concentrations of Copper
}

\author{
Cristina C. Cuchiara ${ }^{1}$, Ilda Mariclei C. Silva ${ }^{1}$, Emanuela G. Martinazzo ${ }^{2}$, Eugenia Jacira B. Braga ${ }^{1}$, \\ Marcos Antonio Bacarin ${ }^{2} \&$ José Antonio Peters ${ }^{1}$ \\ ${ }^{1}$ Laboratório de Cultura de Tecidos de Plantas, Universidade Federal de Pelotas, Instituto de Biologia, \\ Departamento de Botânica, Campus Universitário S/N., CP 354, CEP 96010-900, Capão do Leão, RS, Brazil \\ ${ }^{2}$ Laboratório de Metabolismo Vegetal, Universidade Federal de Pelotas, Instituto de Biologia, Departamento de \\ Botânica, Campus Universitário S/N., CP 354, CEP 96010-900, Capão do Leão, RS, Brazil \\ Correspondence: José Antonio Peters, Laboratório de Cultura de Tecidos de Plantas, Universidade Federal de \\ Pelotas, Instituto de Biologia, Departamento de Botânica, Campus Universitário S/N., CP 354, CEP 96010-900, \\ Capão do Leão, RS, Brazil. Tel: 55-53-3275-7344. E-mail: japeters1@hotmail.com
}

Received: May 6, 2013 Accepted: June 6, 2013 Online Published: July 15, 2013

doi:10.5539/jas.v5n8p8 URL: http://dx.doi.org/10.5539/jas.v5n8p8

\begin{abstract}
This study evaluates the chlorophyll index and fluorescence parameters of chlorophyll $a$ in Alternanthera tenella grown in different concentrations of copper $(\mathrm{Cu})$. The A. tenella plants were hydroponically grown in a complete nutrient solution for 3 days and were then transferred to the same solution containing different copper concentrations [0.041, 0.082 (control), 0.164, 0.246, and $0.328 \mathrm{mM}$ ]. The plants were maintained in these solutions for 13 days. The nutrient solutions were replaced every 3 days, and the plants were evaluated at 6 days and 13 days after the start of the treatment. An increase in the chlorophyll index was observed at copper concentrations of $0.164,0.246$, and $0.328 \mathrm{mM}$ on days 6 and 13. These concentrations of copper also affected the fluorescence parameters and caused a reduction in the pool of the final photosystem I (PSI) electron acceptors, a decrease in the total number of electron carriers per reaction centre, a decrease in the parameters related to the flow, yield, and efficiency for the reduction of the final PSI acceptor, and a decline of the total photosynthetic performance index. Therefore, high doses of copper affect the functionality of the PSI, decreasing the reduction flow of the final PSI electron acceptors.
\end{abstract}

Keywords: plant nutrition, photosynthesis, micronutrient, copper sulphate, JIP-Test

\section{Introduction}

The recent increase in agricultural and industrial activities has contributed to the increased occurrence of heavy metals in the ecosystem. However, plants need minerals, which are mainly acquired from the soil, to maintain normal growth and development and to ensure the completion of their life cycles (Yruela, 2009). Copper $(\mathrm{Cu})$, a transition metal, is an essential micronutrient for plants and exists in two oxidation states in the cellular environment, $\mathrm{Cu}^{2+}$ and $\mathrm{Cu}^{+}$(Yruela, 2005). Copper can be absorbed by the roots of the plant in the form of chelated copper complexes (citric acid, tartaric acid, malic acid, oxalic acid, metallophores, phenols, etc.) and as $\mathrm{Cu}^{2+}$. The translocation of copper to the shoot occurs via the xylem, through the transpiration chain, and for the most part, the copper is complexed with amino acids (Prado, 2008). Inside the cell, copper is required at several locations, such as the cytosol, endoplasmic reticulum, mitochondria, chloroplasts, and apoplasts (Yruela, 2009). Copper also plays a variety of roles in plant metabolic processes including photosynthesis, respiration, antioxidant activity, the biosynthesis of cell wall components, lignification, ethylene detection, and the production of secondary metabolites (Pilon et al., 2006; Burkhead et al., 2009; Lequeux et al., 2010; Perotti et al., 2010).

The majority of the copper in the plant is located in the chloroplasts of the leaves, and more than half this ion is bound to plastocyanin, which is a $\mathrm{Cu}$-containing protein that participates in the transport of electrons between photosystems II and I (PSII and PSI). This electron transport mechanism is affected in plants deficient on the copper (Prado, 2008). The photosynthetic apparatus is sensitive to this cation, and the in the low or high level 
leads to changes in the function of PSII, the rate of electron transfer, and the formation of plastocyanin (Yruela, 2009; Cambrollé et al., 2011).

Considering the importance of photosynthesis for the growth and development of plants, and the sensitivity of the photosynthetic apparatus to environmental stress, the measurement of chlorophyll $a$ fluorescence is an important technique for assessing photosynthetic efficiency, specifically for the behaviour of PSII (Mehta et al., 2010; Buonasera et al., 2011; Yang et al., 2012). The use of this direct, non-destructive, highly sensitive, and reliable technique has provided a greater understanding photosynthetic process (Rohácek, 2002). This technique allows the study of characteristics related to the absorption and transfer of light energy in the electron transport chain in chloroplast (Krause \& Weis, 1991).

Evaluating the chlorophyll $a$ fluorescence allows the calculation of the parameters that estimate the energy absorption by the pigments of the antenna system, the capture of an exciton by the reaction centre, and the subsequent electron transport to the final electron acceptor (Yusuf et al., 2010). From the measurement of the fluorescence transient (OJIP) using the JIP-Test (Strasser \& Strasser, 1995), it is possible to quantify the flux of energy passing through the photosystems, to evaluate the photosynthetic performance of plants, and to analyse the PSII operation (Strasser et al., 2004; Tsimilli-Michael \& Strasser, 2008).

Small concentration and excess of the copper in plant can cause nutritional problems that adversely affect physiological processes, numerous studies have investigated the effect of different concentrations of this element, with particular emphasis on the energy flux and the electron transport chain. This study measured the chlorophyll index and the parameters of the chlorophyll $a$ fluorescence transient in Alternanthera tenella plants grown in nutrient solutions containing different copper concentrations.

\section{Material and Methods}

\subsection{Plant Material and Experimental Conditions}

Alternanthera tenella Colla plants were established and multiplied in vitro and were acclimatised for 2 weeks in a growth chamber under a photosynthetically active photon flux density of $120 \mu \mathrm{mol} \mathrm{m}^{-2} \mathrm{~s}^{-1}$ and a 16-hour photoperiod. Subsequently, the plants were transferred to a continuous-flow root floating hydroponic system and were cultured using Hoagland and Arnon (1938) complete nutrient solution for 3 days. On the fourth day, the plants were transferred to the same nutrient solution containing the copper concentrations $0.041,0.082,0.164$, 0.246 , and $0.328 \mathrm{mM}$, provided in the form of copper sulphate $\left(\mathrm{CuSO}_{4} \cdot 5 \mathrm{H}_{2} \mathrm{O}\right)$. These concentrations were chosen according to preliminary tests with other plant species, which showed that the cultivation until the copper concentration of $0.082 \mathrm{mM}$ did not show physiological changes (data not shown). Then, the concentration of $0.082 \mathrm{mM}$ copper was employed as control. The plants were maintained under the same conditions of photon flux density and photoperiod for further 13 days. The solutions were changed every 3 days, and the chlorophyll $a$ fluorescence transient and chlorophyll content were measured on days 6 and 13 after the start of the treatment (after transfer to solution with different copper concentration).

\subsection{Chlorophyll Index and Chlrophyll a Fluorescence Transient}

The chlorophyll content was estimated using a CL-01 portable chlorophyll meter (Hansatech Instruments Ltd., King's Lynn, Northfolk, UK), and the results are expressed as the "chlorophyll index" (Cassol et al., 2008).

The chlorophyll $a$ fluorescence transient was measured in fully expanded leaves from 16 plants grown at each copper concentration, using a Handy-Pea portable fluorometer (Hansatech Instruments Ltd., King's Lynn, Norkfolk, UK). The measurements were performed on non-detached leaves that were previously adapted to the dark for 30 minutes for the complete oxidation of the photosynthetic electron transport system, and the fluorescence intensity was measured for $1 \mathrm{~s}$ after the application of a saturating light pulse of $3,000 \mu \mathrm{mol} \mathrm{m}^{-2} \mathrm{~s}^{-1}$. The JIP-Test parameters were calculated based on the fluorescence intensities at $50 \mu \mathrm{s}$ (minimum fluorescence), $100 \mu \mathrm{s}, 300 \mu \mathrm{s}, 2 \mathrm{~ms}\left(\mathrm{~F}_{\mathrm{J}}\right), 30 \mathrm{~ms}\left(\mathrm{~F}_{\mathrm{I}}\right)$, and $\mathrm{F}_{\mathrm{M}}$ (maximum fluorescence) (Strasser \& Strasser, 1995). The kinetic analysis of the chlorophyll $a$ transient was evaluate by variable fluorescence between the steps OK, OJ and OI, by normalisation as follows: $\mathrm{W}_{\mathrm{OK}}=\left[\left(\mathrm{F}_{\mathrm{t}}-\mathrm{F}_{0}\right) /\left(\mathrm{F}_{\mathrm{K}}-\mathrm{F}_{0}\right)\right], \mathrm{W}_{\mathrm{OJ}}=\left[\left(\mathrm{F}_{\mathrm{t}}-\mathrm{F}_{0}\right) /\left(\mathrm{F}_{\mathrm{J}}-\mathrm{F}_{0}\right)\right]$, and $\mathrm{W}_{\mathrm{OI}}=\left[\left(\mathrm{F}_{\mathrm{t}}-\mathrm{F}_{0}\right) /\left(\mathrm{F}_{\mathrm{I}}-\mathrm{F}_{0}\right)\right]$, respectively. Additionally, the differences between the $\Delta \mathrm{W}_{\mathrm{OK}}$ and $\Delta \mathrm{W}_{\mathrm{OJ}}$ transients relative to the control treatment $(0.082 \mathrm{mM})$ were assessed as $\Delta \mathrm{W}_{\mathrm{OK}}=\left[\mathrm{W}_{\mathrm{OK}(\text { stress) }}-\mathrm{W}_{\mathrm{OK}(\text { control })}\right]$ and $\Delta \mathrm{W}_{\mathrm{OJ}}=\left[\mathrm{W}_{\mathrm{OJ}(\text { stress) }}-\mathrm{W}_{\mathrm{OJ}(\text { control) }}\right]$ (Yusuf et al., 2010).

\subsection{Statistical Analysis}

The experiment was performed using a completely randomised design consisting of five doses of copper ( 0.041 , $0.082,0.164,0.246$, and $0.328 \mathrm{mM}$ ) and four replicates (four plants per replicate). The response variables were evaluated at twice (on days 6 and 13) during exposure to the copper stress. The experiment was repeated twice. 
The chlorophyll index was subjected to analysis of variance (ANOVA), and the means were compared using Tukey's test at $5 \%$ significance.

\section{Results}

\subsection{Chlorophyll Index}

At 6 and 13 days of the stress treatment we observed that the chlorophyll index were more high in plant treated with higher doses of copper (Figure 1), and when we reduced the copper concentration for $0.041 \mathrm{mM} \mathrm{Cu}$, the chlorophyll index not differed of the concentration control $(0.082 \mathrm{mM})$.

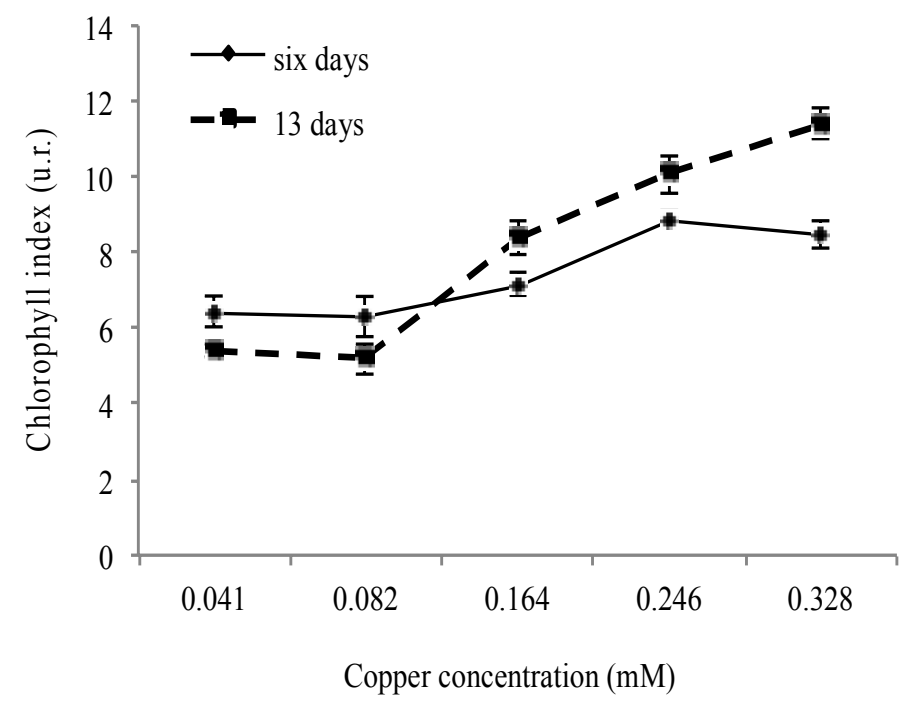

Figure 1. Chlorophyll index (relative unit) of Alternanthera tenella Colla plants subjected to different concentrations of $\mathrm{Cu}$ on days 6 (----) and 13 (----) of the stress treatment. Bar indicates the standard error of the mean $(n=16)$

\subsection{Chlorophyll a Fluorescence Transient: Normalisation and Subtraction of Transients (OJIP)}

The different copper doses had no marked effects on the chlorophyll $a$ fluorescence transient (Figure 2A-2B) or on the relative variable fluorescence between steps $\mathrm{O}$ and $\mathrm{P}\left[\left(\mathrm{V}_{\mathrm{OP}}=\left(\mathrm{F}_{\mathrm{t}}-\mathrm{F}_{0}\right) /\left(\mathrm{F}_{\mathrm{M}}-\mathrm{F}_{0}\right)\right]\right.$ (Figure $\left.2 \mathrm{C}-2 \mathrm{D}\right)$ obtained on days 6 and 13 after the start of the experiment. The normalisation and subtraction of transients between steps $\mathrm{OK}$ and OJ allows the verification of the appearance of the K-band (approximately $300 \mu \mathrm{s}$ ) and L-bands (approximately $150 \mu \mathrm{s}$ ). In present study the copper had no effect on the relative variable fluorescence between steps $\mathrm{O}(50 \mu \mathrm{s})$ and $\mathrm{K}(300 \mu \mathrm{s})$ or steps $\mathrm{O}(50 \mu \mathrm{s})$ and $\mathrm{J}(2 \mu \mathrm{s})$; thus, the $\mathrm{K}-$ and L- bands were not visualised (data not shown).

To investigate the effect of the different copper doses on the fluorescence transient IP phase, the following procedures, proposed by Yusuf et al. (2010), were followed: a) the interpretation of the relative variable fluorescence curve between steps $\mathrm{O}$ and I with values greater than or equal to 1 ( $\mathrm{W}_{\mathrm{OI}} \geq 1$ ) (Figure $3 \mathrm{~A}-3 \mathrm{~B}$ ), and $\mathrm{b}$ ) the analysis of the normalised transients between steps $\mathrm{I}$ and $\mathrm{P}$ as relative variable fluorescence $\left[\mathrm{W}_{\mathrm{IP}}=\left(\mathrm{F}_{\mathrm{t}}-\mathrm{F}_{\mathrm{I}}\right) /\left(\mathrm{F}_{\mathrm{M}}-\mathrm{F}_{\mathrm{I}}\right)\right]$ represented on a linear scale between 30 and $330 \mathrm{~ms}$ (Figure 3C-3D). On days 6 and 13, the size of the final PSI electron acceptor pool decreased at the higher copper doses (Figure 3A-3B). On day 6, the results from the lowest treatment dose were similar to the control dose, whereas on day 13, the size of the final PSI electron acceptor pool was inversely proportional to the dose, i.e., lower doses produced a larger pool (Figure 3B). Yusuf et al. (2010) proposed that for each curve, the maximal amplitude of the fluorescence rise reflects the size of the pool of the end electron acceptors at the PS I acceptor side. In other hand, the estimated the overall rate constant (inverse of the half-time - i.e., the inverse of the time to reach a $\mathrm{W}_{\mathrm{IP}}=0.5$ ) of the PSI electron acceptors, did not show differences among the copper doses at the two periods analysed (Figure 3C-3D). 

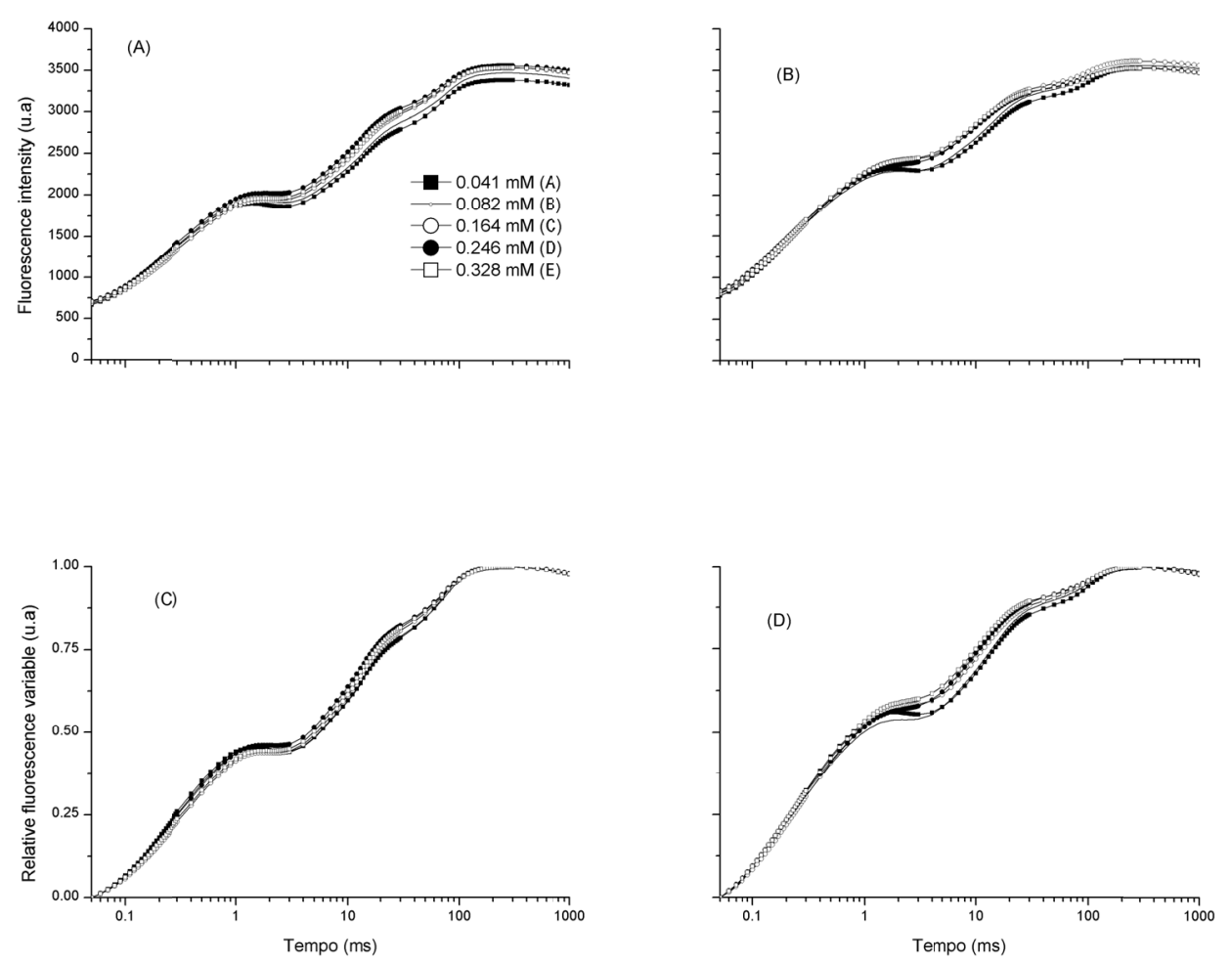

Figure 2. Chlorophyll $a$ fluorescence transient of dark-adapted leaves of Alternanthera tenella Colla plants subjected to different $\mathrm{Cu}$ concentrations. A, B - Fluorescence intensity $\left(\mathrm{F}_{\mathrm{t}}\right)$; C, D - Relative variable fluorescence $\left[\mathrm{V}_{\mathrm{OP}}=\left(\mathrm{F}_{\mathrm{t}}-\mathrm{F}_{0}\right) /\left(\mathrm{F}_{\mathrm{M}}-\mathrm{F}_{0}\right)\right]$. Plants were subjected to stress for $6(\mathrm{~A}, \mathrm{C})$ and $13(\mathrm{~B}, \mathrm{D})$ days
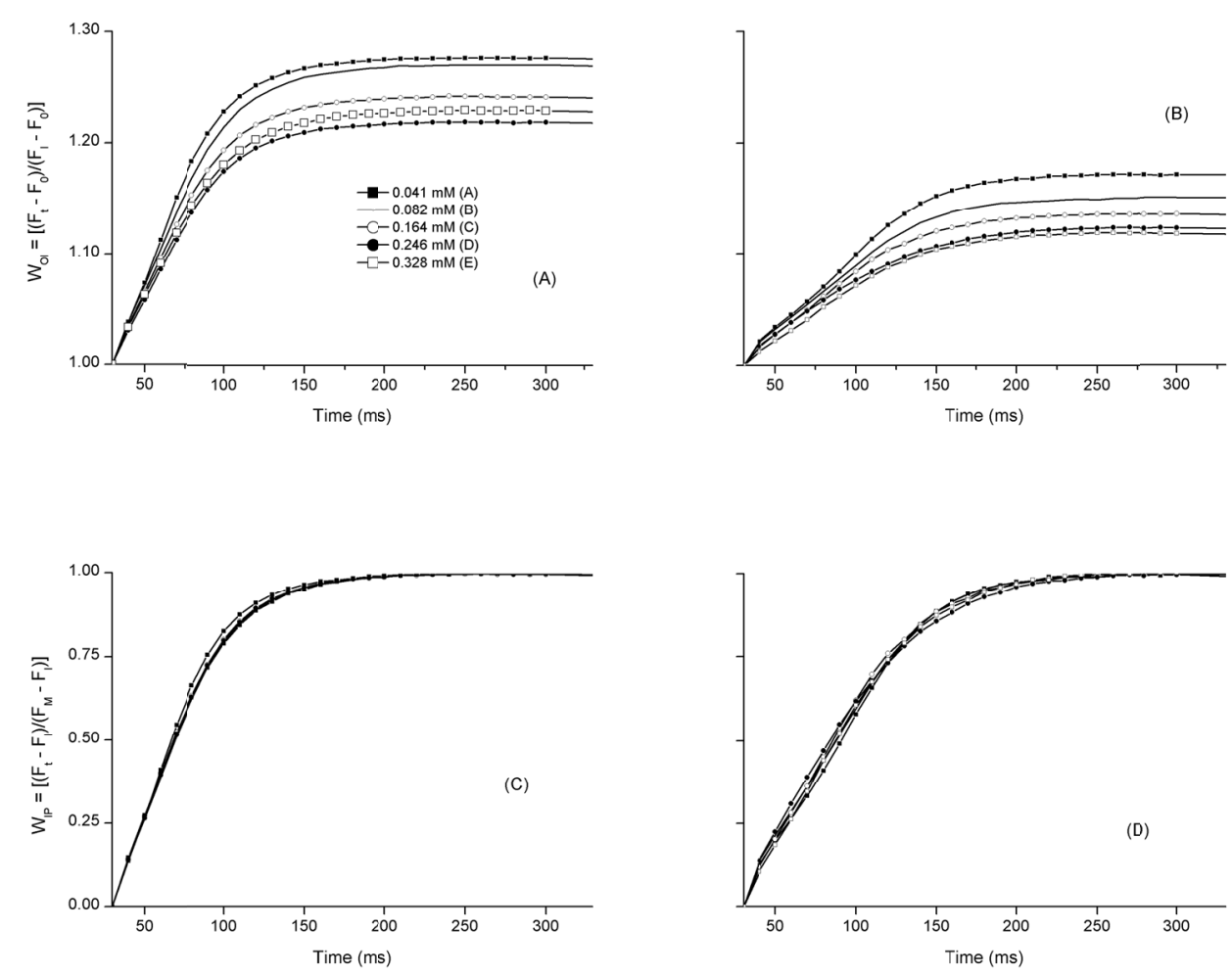

Figure 3. Chlorophyll $a$ fluorescence transient of dark-adapted Alternanthera tenella Colla subjected to different $\mathrm{Cu}$ concentrations. A, B - Variable fluorescence between steps $\mathrm{O}$ and $\mathrm{I}\left[\mathrm{W}_{\mathrm{OI}}=\left(\mathrm{F}_{\mathrm{t}}-\mathrm{F}_{0}\right) /\left(\mathrm{F}_{\mathrm{I}}-\mathrm{F}_{0}\right)\right]$ in the 30 to $330 \mathrm{~ms}$ time interval; C, D - Variable fluorescence between steps I and $\mathrm{P}\left[\mathrm{W}_{\mathrm{IP}}=\left(\mathrm{F}_{t}-\mathrm{F}_{\mathrm{I}}\right) /\left(\mathrm{F}_{\mathrm{P}}-\mathrm{F}_{\mathrm{I}}\right)\right]$. Plants were subjected to stress for $6(\mathrm{~A}, \mathrm{C})$ and $13(\mathrm{~B}, \mathrm{D})$ days 


\subsection{Chlorophyll a Fluorescence Transient: PSII Biophysical Parameters Derived from the JIP-test Equations}

The JIP-Test parameters are shown in the form of a radar chart, and all of the fluorescence parameter values were normalised to the values determined by the values for plants grown under the control treatment $(0.082 \mathrm{mM}$ $\mathrm{Cu}$ ) on days 6 and 13 of the stress treatment (Figure 4A-4B).

The stress did not affect the normalised total complementary area above the transient curve only for the OJ phase $\left(\mathrm{S}_{\mathrm{S}}\right)$, which reflects single-turnover $\mathrm{Q}_{\mathrm{A}}$ reduction events (Chen et al., 2011). In contrast, lower value in the normalised total complementary area above the transient curve $\left(S_{m}=E C_{0} / R C\right)$ was observed for the treatments with copper concentrations above $0.164 \mathrm{mM}$ on day 6 and 13 of the stress, but the reduction was most obvious on 7 days. A similar effect was observed for the number of reduction turnovers, oxidation and re-reduction of $Q_{A}$ in the time between turning on the light and reaching the $F_{M}(N)$.

The specific flux (flux per active PSII reaction centre) of absorption (ABS/RC), trapping $\left(\mathrm{TR}_{0} / \mathrm{RC}\right)$ and electron transport $\left(\mathrm{ET}_{0} / \mathrm{RC}\right)$ showed little reduction compared to the control on days 6 and 13 of the stress treatment (Figure 4A-4B). However, the reduction flux of the final PSI electron acceptors $\left(\mathrm{RE}_{0} / \mathrm{RC}\right)$ was the parameter that exhibited the greatest reduction above the control $(0.082 \mathrm{mM})$ both on day 6 and 13 of the stress. At 13 days we observed that the plants exposed to $0.041 \mathrm{mM} \mathrm{Cu}$ exhibited an $\mathrm{RE}_{0} / \mathrm{RC}$ that was greater than the control (Figure 4B).
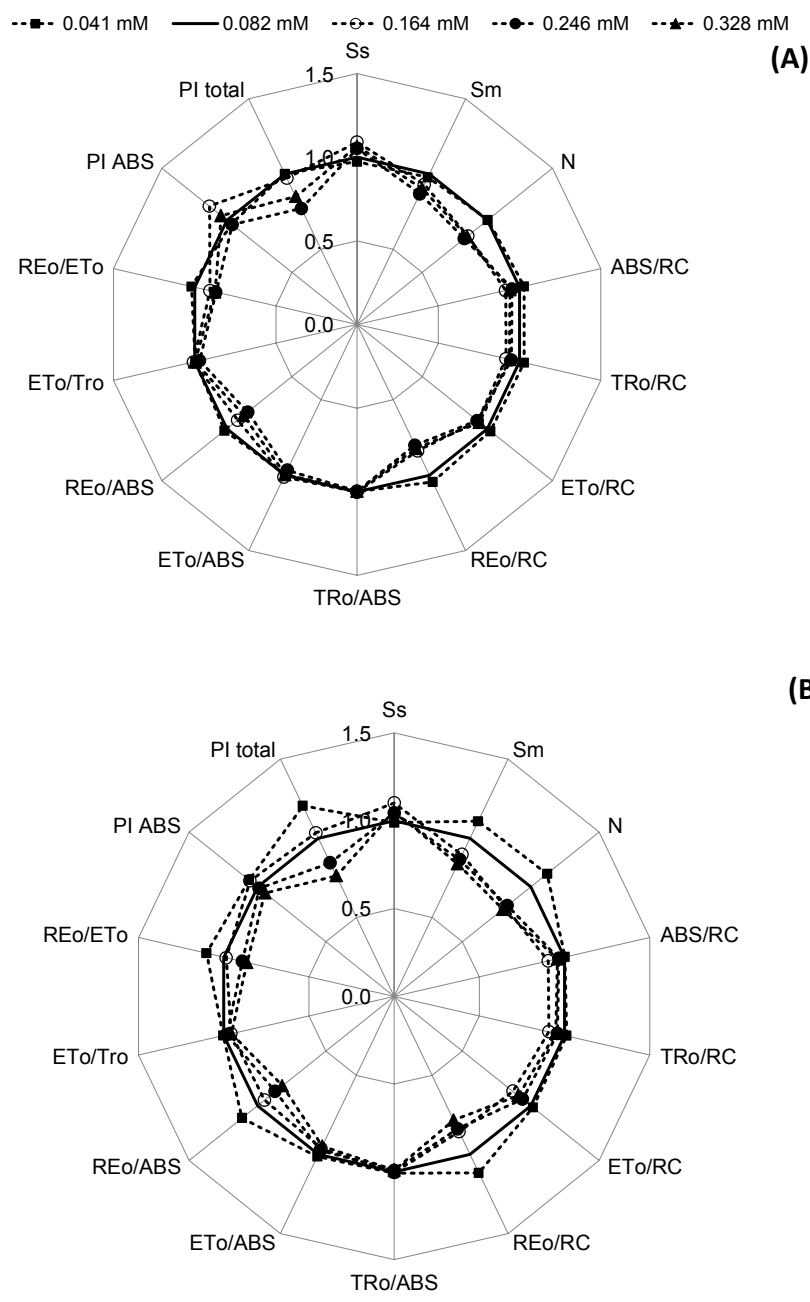

(B)

Figure 4. Chlorophyll $a$ fluorescence parameters deduced from the JIP-Test analysis of fluorescence transient of Alternanthera tenella Colla plants subjected to different $\mathrm{Cu}$ concentrations $(0.041,0.082,0.164,0.246$, and 0.328 $\mathrm{mM}$ ). Plants were subjected to stress for 6 (A) and 13 (B) days 
The quantum yields data demonstrated that a) the maximum photochemical quantum yield $\left(\varphi_{\mathrm{Po}_{0}}=\mathrm{TR}_{0} / \mathrm{ABS}\right)$ and the quantum yield of the electron transport from $\mathrm{Q}_{\mathrm{A}}{ }^{-}$to the intersystem of electron acceptors $\left(\varphi_{\mathrm{E} o}=\mathrm{ET}_{0} / \mathrm{ABS}\right)$ were not affected by the copper doses or by the period of stress, and $b$ ) the quantum yield for the reduction of the final PSI electron acceptor per photon absorbed $\left(\varphi_{\mathrm{Ro}}=\mathrm{RE}_{0} / \mathrm{ABS}\right)$ followed that observed for the $\mathrm{RE}_{0} / \mathrm{RC}$. The efficiency parameters did not demonstrate differences in the $\psi_{\mathrm{Eo}}=\mathrm{ET}_{0} / \mathrm{TR}_{0}$ (probability/efficiency in which an exciton captured in the reaction centre can move an electron from the $\mathrm{Q}_{\mathrm{A}}{ }^{-}$to the intersystem of the electron acceptors); however, the $\delta_{\mathrm{Ro}}=\mathrm{RE}_{0} / \mathrm{ET}_{0}$ (efficiency/probability that an electron of the intersystem electron carriers moves to reduce the final PSI electron acceptors or the likelihood of the reduction of a final PSI acceptor) decreased in the plants subjected to copper concentrations higher than the control on day 6 of the stress (Figure 4A) and in plants subjected to 0.246 and $0.328 \mathrm{mM} \mathrm{Cu}$ on day 13 of the stress (Figure 4B). However, the plants treated with $0.041 \mathrm{mM} \mathrm{Cu}$ exhibited a higher $\mathrm{RE}_{0} / \mathrm{ET}_{0}$ compared to the control on day 13 of the stress.

On day 6 of the stress treatment, the performance index based on the absorption ( $\left.\mathrm{PI}_{\mathrm{ABS}}\right)$ (Strasser et al., 2004) showed a slightly higher value in the plants exposed to $0.164 \mathrm{mM} \mathrm{Cu}$, whereas the other doses of copper did not induce changes in this parameter at this time point (Figure $4 \mathrm{~A}$ ). No differences in the $\mathrm{PI}_{\mathrm{ABS}}$ were observed on day 13 of the stress treatment (Figure 4B). However, the analysis of the total photosynthetic performance index $\left(\mathrm{PI}_{\text {total }}\right)$, which measures the performance of electron flux to the final PSI electron acceptors (proposed by Tsimilli-Michael \& Strasser (2008)), demonstrated that i) a reduction of the $\mathrm{PI}_{\text {total }}$ was observed on day 6 of the stress treatment at doses above the control and ii) on day 13 of the stress treatment, the plants exposed to 0.041 $\mathrm{mM} \mathrm{Cu}$ exhibited an increase in the $\mathrm{PI}_{\text {total }}$, whereas the plants grown at higher doses of $\mathrm{Cu}(0.246$ and $0.328 \mathrm{mM})$ exhibited a reduction in the $\mathrm{PI}_{\text {total }}$.

\section{Discussion}

The copper is an essential micronutrient for plant growth and is a component of many proteins, especially those involved in the photosynthetic (plastocyanin) and respiratory (cytochrome oxidase) electron transport chains (Pilon et al., 2006). However, high concentrations of copper are potentially toxic to most plants and the effects of this element on biochemical and physiological functions have been studied extensively. It has been recognised that copper toxicity induces the inhibition of the photosynthetic processes (Cambrollé et al., 2011).

The effect of metal ions on the photosynthetic pigments in algae and higher plants has been addressed in several studies; however, it has often proven difficult to distinguish the indirect effects of the elements on the plant metabolism. A reduction in the chlorophyll content with higher concentrations of copper and iron has been reported by Mourato et al. (2009) in yellow lupine (Lupinus luteus L.) and by Adamski et al. (2011) in sweet potato (Ipomoea batatas L.), respectively. This effect on the chlorophyll content is common for metal ion toxicity in plants. In this study, the copper had an inverse effect on the chlorophyll index, which is a widely used method for estimating the photosynthetic potential of plants because of the direct connection between the absorption and transfer of light energy, growth and adaptation to different environments (Almeida et al., 2004). Based on the association of the chlorophyll index values with the growth of plants in the presence of high doses of copper, it is possible that the increased concentration of this micronutrient enhanced the chlorophyll index values by decreasing the leaf area and the fresh and/or dried leaf tissue (data not shown) at the two evaluated time points, as shown by McMahon and Kelly (1990).

The use of chlorophyll $a$ fluorescence in dark-adapted leaves has provided a greater understanding of the photosynthetic apparatus and its efficiency (Strasser et al., 2000). The chlorophyll $a$ fluorescence transient curves in the plants exposed to different concentrations of copper (Figure 2A-2B) demonstrated a typical OJIP curves. The analysis of the transient kinetic differences between steps $\mathrm{O}$ and $\mathrm{K}\left(\Delta \mathrm{W}_{\mathrm{OK}}\right)$ and steps $\mathrm{O}$ and $\mathrm{J}\left(\Delta \mathrm{W}_{\mathrm{OJ}}\right)$ did not result in the appearance of the L- and K- bands, respectively. The failure to identify the L band suggests the maintenance of the energetic connectivity (grouping) of the PSII units, as demonstrated by Strasser and Stirbet (1998), and taking into account that the K- band was not identified, it can be inferred that the oxygen-evolution complex was not inactivated, as demonstrated by Yusuf et al. (2010).

The analysis of the IP phase transient (Figure 3A-3B) demonstrated that the effect of stress (high doses of copper) was reflected by the decline in the size of the electron acceptor pool of the PSI acceptor site (Redillas et al., 2011a). However, when comparing the transient analyses $\mathrm{W}_{\mathrm{OI}}$ (Figure 3A-3B) and $\mathrm{W}_{\mathrm{IP}}$ (Figure 3C-3D), it was observed that the decrease in the pool size was not associated with the regulation of the overall reduction rate of the PSI electron acceptors, suggesting that the regulation of these two parameters is independent. A similar response was observed in Brassica juncea plants overexpressing the $\alpha$-tocopherol methyltransferase gene and treated with $\mathrm{NaCl}, \mathrm{CdCl}_{2}$, and mannitol (Yusuf et al., 2010) and in rice plants (Oryza sativa cv. Nipponbare) grown under nitrogen-limited conditions (Redillas et al., 2011b). 
The use of the JIP-Test permits the understanding of processes related to energy flux in the electron transport chain, and this test is commonly used to discriminate plants grown under normal conditions from those grown under stress conditions (Redillas et al., 2011b). The flux starts with the absorption of light by the pigments of the PSII antenna and ends with the reduction of the final PSI electron acceptors (Yusuf et al., 2010). In this study, the interpretation of the JIP-Test parameters associated with the fluorescence emission kinetic analysis, especially in the IP-phase, demonstrated that different copper concentrations induced variations in the phase of the electron transport chain related to the reduction of the final PSI electron acceptors.

The analysis of the JIP-Test parameters demonstrated that compared to the control, the plants grown with high doses of copper demonstrated a smaller total complementary area above the OJIP or a reduced ability to transport electrons per reaction centre $\left(\mathrm{S}_{\mathrm{m}}=\mathrm{EC}_{0} / \mathrm{RC}\right)$, indicating that less energy is needed to close all of the reaction centres (Strasser et al., 2000). According to Stirbet and Govindjee (2011), the $S_{m}$ is proportional to the number of electrons passing through the electron transport chain (i.e., multiple-turnover $\mathrm{Q}_{\mathrm{A}}$ reduction events), with $\mathrm{N}=\mathrm{S}_{\mathrm{m}} / \mathrm{S}_{\mathrm{s}}$ (where $\mathrm{S}_{\mathrm{s}}$ only represents the complementary normalised area between the OJ phase, reflecting single-turnover $\mathrm{Q}_{\mathrm{A}}$ reduction events), i.e., $\mathrm{N}$ is the number of times that $\mathrm{Q}_{\mathrm{A}}$ becomes reduced and re-oxidised, until the maximum fluorescence $\mathrm{F}_{\mathrm{M}}$ (i.e., the number of turns) is reached. Based on this equation, it was possible to show that the dose-dependent changes initiated in the PSII, i.e., for the evaluation of parameters describing the oxidation and reduction of the PSII electron acceptors $\left(\mathrm{S}_{\mathrm{m}}\right.$ and $\left.\mathrm{N}\right)$.

Thus, the results show that the flux $\left(\mathrm{RE}_{0} / \mathrm{RC}\right)$, the yield $\left(\varphi_{\mathrm{R} 0}=\mathrm{RE} / \mathrm{ABS}\right)$, and the efficiency $\left(\delta_{0}=\mathrm{RE}_{0} / \mathrm{ET}_{0}\right)$ may have been the limiting factors in the flux of electrons that permit the reduction of plastoquinone in the PSII. It can be inferred that high doses of copper are toxic in plants, stimulating metal detoxification mechanisms, such as complexation (Hänsch \& Mendel, 2009), thus limiting the availability of this element for the plastocyanin molecule, which is responsible for maintaining intersystem electron transport to the PSI. Together, the parameters of the chlorophyll fluorescence transient indicates that increasing the dose of copper reduced the photochemical and non-photochemical redox reactions in the plants subjected to copper stress for 6 and 13 days, which is also reflected by the reduction of the $\mathrm{PI}_{\text {total }}$.

The performance indices $\left(\mathrm{PI}_{\mathrm{ABS}}\right.$ and $\left.\mathrm{PI}_{\text {total }}\right)$ are reflect the conservation of energy from photons absorbed by the PSII antenna system; changes in these indices are considered good indicators of photosynthetic activity or even stress that directly or indirectly damages the photosynthetic apparatus in plants (Stirbet \& Govindjee, 2011). The $\mathrm{PI}_{\mathrm{ABS}}$ index provides complete and quantitative information regarding the vitality of plants (Strasser et al., 2004). A slight increase in the $\mathrm{PI}_{\mathrm{ABS}}$ after 6 days of exposure to $0.164 \mathrm{mM} \mathrm{Cu}$ can be interpreted as an adaptation to the initial stress, i.e., a compensation for its low photosynthetic capacity (Oukarroum et al., 2009) and/or this can be attributed to the higher RC/ABS component values observed for these plants. The $\mathrm{PI}_{\text {total }}$ index has been described as the most sensitive parameter of the JIP-Test, measuring the partial energy conservation potential to the final PSI electron acceptors (Tsimilli-Michael \& Strasser, 2008; Yusuf et al., 2010). According to Yusuf et al. (2010), a negative or positive $\mathrm{PI}_{\text {total }}$ expresses a "loss" or "gain", respectively, of the energy conservation capacity, and this value is considered an efficient tool to quantify stress in plants. A decrease in the $\mathrm{PI}_{\text {total }}$ in plants subjected to high doses of copper not only resulted in the loss of PSII activity but also caused structural and/or functional damage to the PSI.

This study showed that $A$. tenella plants grown in high concentrations of copper did not exhibit differences in the capture and absorption of energy by the PSII; however, an impairment of the PSI related parameters was observed. The excess copper caused the following effects: a reduction in the size of the final PSI electron acceptor pool, a reduction in the total number of electron carriers per reaction centre, and a decrease in the parameters related to the flow, yield, and efficiency of reduction of the final PSI acceptors, as evidenced by the reduction of the $\mathrm{PI}_{\text {total }}$. Therefore, the high doses of copper predominantly affect the structure and functionality of the PSI.

\section{Acknowledgements}

This work was supported by the Coordination of Improvement of Higher Education Personnel (Coordenação de Aperfeiçoamento de Pessoal de Nível Superior - CAPES), by the National Council for Scientific and Technological Development (Conselho Nacional de Desenvolvimento Científico e Tecnológico - CNPq), and the Financier of Studies and Projects (Financiadora de Estudos e Projetos - FINEP/MCT).

\section{References}

Adamski, J. M., Peters, J. A., Danieloski, R., \& Bacarin, M. A. (2011). Excess iron-induced changes in the photosynthetic characteristics of sweet potato. Journal of Plant Physiology, 168, 2056-2062. http://dx.doi.org/10.1016/j.jplph.2011.06.003 
Almeida, L. P., Alvarenga, A. A., Castro, E. M., Zanela, S. M., \& Vieira, C. V. (2004). Early growth of plants of Cryptocaria aschersoniana Mez. submitted to radiation solar levels. Ciência Rural, 34(1), 83-88. http://dx.doi.org/10.1590/S0103-84782004000100013

Buonasera, K., Lambreva, M., Rea, G., Touloupakis, E., \& Giardi, M. T. (2011). Technological applications of chorophyll a fluorescence for the assessment of environmental pollutants. Analytical and Bioanalytical Chemistry, 401, 1139-1151. http://dx.doi.org/10.1007/s00216-011-5166-1

Burkhead, J. L., Gogolin Reynolds, K. A., Abdel-Ghany, S. E., Cohu, C. M., \& Pilon, M. (2009). Copper homeostasis. New Phytologist, 182, 799-816. http://dx.doi.org/10.1111/j.1469-8137.2009.02846.x

Cambrollé, J., Mateos-Naranjo, E., Redondo-Gómez, S., Luque, T., \& Figueroa, M. E. (2011). Growth, reproductive and photosynthetic responses to copper in the yellow-horned poppy. Glaucium flavum Crantz. Environmental and Experimental Botany, 71, 57-64. http://dx.doi.org/10.1016/j.envexpbot.2010.10.017

Cassol, D., Silva, F. S. P., Falqueto, A. R., \& Bacarin, M. A. (2008). An evaluation of non-destructive methods to estimate total chlorophyll content. Photosynthetica, 46, 634-636. http://dx.doi.org/10.1007/s11099-008-0109-6

Chen, S., Zhou, F., Yin, C., Strasser, R. J., Yang, C., \& Qiang, S. (2011). Application of fast chlorophyll a fluorescence kinetics to probe action target of 3-acetyl-5-isopropyltetramic acid. Environmental and Experimental Botany, 71, 269-279. http://dx.doi.org/10.1016/j.envexpbot.2010.12.013

Hänsch, R., \& Mendel, R. R. (2009). Physiological functions of mineral micronutrients (Cu, Zn, Mn, Fe, Ni, Mo, B, Cl). Current Opinion in Plant Biology, 12, 259-266. http://dx.doi.org/10.1016/j.pbi.2009.05.006

Hoagland, D. R., \& Arnon, D. (1938). The water-culture method for growing plants without soil. Berkeley, California, University of California College of Agriculture, Agricultural Experimental Station. Circular, 347, 1-39. Retrieved January 20, 2013, from http://www.scielo.br/scielo.php?script=sci_nlinks\&ref=000043\&pid=S0100-8358200000010000200009\&1 $\mathrm{ng}=\mathrm{en}$

Krause, G. H., \& Weis, E. (1991). Chlorophyll fluorescence and photosynthesis: the basics. Annual Review of Plant Physiology, 42, 313-349. http://dx.doi.org/10.1146/annurev.pp.42.060191.001525

Lequeux, H., Hermans, C., Lutts, S., \& Verbruggen, N. (2010). Response to copper excess in Arabidopsis thaliana: Impact on the root system architecture, hormone distribution, lignin accumulation and mineral profile. Plant Physiology and Biochemistry, 48(8), 673-682. http://dx.doi.org/10.1016/j.plaphy.2010.05.005

McMahon, M. J., \& Kelly, J. W. (1990). Influence of spectral filters on height, leaf chlorophyll, and flowering of Rosa x hybrida 'Meirutral'. Journal of Environmental Horticulture, 8(4), 209-211.

Mehta, P., Jajoo, A., Mathur, S., \& Bharti, S. (2010). Chlorophyll a fluorescence study revealing effects of high salt stress on photosystem II in wheat leaves. Plant Physiology and Biochemistry, 48, 16-20. http://dx.doi.org/10.1016/j.plaphy.2009.10.006

Mourato, M. P., Martins, L. L., \& Campos-Andrada, M. P. (2009). Physiological responses of Lupinus luteus to different copper concentrations. Biologia Plantarum, 53(1), 105-111. http://dx.doi.org/10.1007/s10535-009-0014-2

Perotti, J. C., Rodrigues, I. C. S., Kleinowski, A. M., Ribeiro, M. V., Einhardt, A. M., Peters, J. A., ... Braga, E. J. B. (2010). Betacyanin production in alligator weed, grown in vitro, with different concentrations of copper sulfate. Ciência Rural, 40(9), 1874-1880. http://dx.doi.org/10.1590/S0103-84782010000900004

Pilon, M., Abdel-Ghany, S. E., Cohu, C. M., Gogolin, K. A., \& Ye, H. (2006). Copper cofactor delivery in plant cells. Current Opinion in Plant Biology, 9, 256-263. http://dx.doi.org/10.1016/j.pbi.2006.03.007

Prado, R. M. (2008). Nutrição de Plantas. São Paulo, SP: Editora UNESP.

Redillas, M. C. F. R., Jeong, J. S., Strasser, R. J., Kim, Y. S., \& Kim, J. K. (2011b). JIP analysis on rice (Oryza sativa cv Nipponbare) grown under limited nitrogen conditions. Journal of Korean Society of Applied Biological Chemistry, 54(5), 827-832, 2011b. http://dx.doi.org/10.3839/jksabc.2011.127

Redillas, M. C. F. R., Strasser, R. J., Jeong, J. S., Kim, Y. S., \& Kim, J. K. (2011a). The use of JIP test to evaluate drought-tolerance of transgenic rice overexpressing OsNAC10. Plant Biotechnology Report, 5, 169-175. http://dx.doi.org/10.1007/s11816-011-0170-7 
Rohácek, K. (2002). Chlorophyll fluorescence parameters: the definitions, photosynthetic meaning, and mutual relationships. Photosynthetica, 40, 13-29. http://dx.doi.org/10.1023/A:1020125719386

Stirbet, A., \& Govindjee. (2011). On the relation between the Kautsky effect (chlorophyll a fluorescence induction) and Photosystem II: Basics and applications of the OJIP fluorescence transient. Journal of Photochemistry and Photobiology B, 104, 236-257. http://dx.doi.org/10.1016/j.jphotobiol.2010.12.010

Strasser, B. J., \& Strasser, R. J. (1995). Measuring fast fluorescence transients to address environmental questions: the JIP-test. In P. Mathis (Ed.), Photosynthesis: From Light to Biosphere (pp. 977-980). The Netherlands, ND: Kluwer Academic Publishers.

Strasser, R. J., \& Stirbet, A. D. (1998). Heterogeneity of Photosystem II probed by the numerically simulated chlorophyll a fluorescence rise (O-J-I-P). Mathematics and Computers Simulation, 48, 3-9. http://dx.doi.org/10.1016/S0378-4754(98)00150-5

Strasser, R. J., Srivastava, A., \& Tsimilli-Michael, M. (2000). The fluorescence transient as a tool to characterize and screen photosynthetic samples. In M. Yunus, U. Pathre, \& P. Mohanty (Eds.), Probing Photosynthesis: Mechanism, Regulation and Adaptation (pp. 443-480). London, UK: Taylor and Francis.

Strasser, R. J., Tsimilli-Michael, M., \& Srivastava, A. (2004). Analysis of the fluorescence transient. In G. C. Papageorgiou \& Govindjee (Eds.), Chlorophyll Fluorescence: A Signature of Photosynthesis (pp. 321-362). Dordrecht, ND: Springer.

Tsimilli-Michael, M., \& Strasser, R. J. (2008). In vivo assessment of plants' vitality: applications in detecting and evaluating the impact of Mycorrhization on host plants. In A. Varma (Ed.), Mycorrhiza: State of the Art, Genetics and Molecular Biology, Eco-Function, Biotechnology, Eco-Physiology, Structure and Systematics (pp. 679-703). Dordrecht, ND: Springer.

Yang, G., Yang, L., Jiang, Y. L., Li, Y., Wang, P., \& Chen, L. (2012). Physiological impacts of magnesium-deficiency in Citrus seedlings: photosynthesis, antioxidant system and carbohydrates. Trees Structure and Function, 26(4), 1237-1250. doi: 10.1007/s00468-012-0699-2

Yruela, I. (2005). Copper in plants. Brazilian Journal of Plant Physiology, 17(1), 145-156. http://dx.doi.org/10.1590/S1677-04202005000100012

Yruela, I. (2009). Copper in plants: acquisition, transport and interactions. Funcional Plant Biology, 36(5), 409-430. http://dx.doi.org/10.1071/FP08288

Yusuf, M. A., Kumar, D., Rajwanshi, R., Strasser, R. J., Tsimilli-Michael, M., Govindjee, \& Sarin, N. B. (2010). Overexpression of $\gamma$-tocopherol methyltransferase gene in transgenic Brassica juncea plants alleviates abiotic stress: Physiological and chlorophyll a fluorescence measurements. Biochimica et Biophysica Acta, 1797, 1428-1438. http://dx.doi.org/10.1016/j.bbabio.2010.02.002

\section{Copyrights}

Copyright for this article is retained by the author(s), with first publication rights granted to the journal.

This is an open-access article distributed under the terms and conditions of the Creative Commons Attribution license (http://creativecommons.org/licenses/by/3.0/). 